\title{
Effectiveness of Public and Co-operative Health Insurance Models in Nepal: A Concurrent Mixed Study
}

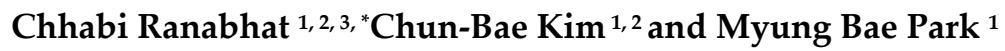 \\ 1 Department of Preventive Medicine, Wonju College of Medicine Yonsei University, Wonju, \\ Gangwon 220-701, Korea \\ 2 Institute for Poverty Alleviation and International Development, Yonsei University Wonju, \\ Gangwon 220-710, Korea \\ ${ }^{3}$ Health Science Foundations and Study Center, Kathmandu, Nepal \\ * Corresponding Author: Chun-Bae Kim, email: kimcb@yonsei.ac.kr and Chhabi Ranabhat, email: \\ chhabir@gmail.com; Tel: +82337410347, Fax: +82337470409
}

\section{Abstract \\ Background}

Health insurance (HI) run by government is providing health care service to large population. Due to poor accountability, participation and sustainability, cooperative health insurance is becoming more popular and effective in low and middle income and some high-income countries too. In Nepal, there are public and cooperative $\mathrm{HI}$ is in practice. The aim of this study is to compare the effectiveness of public (government) and cooperative $\mathrm{HI}$ in relation to benefit packages, population coverage, inclusiveness, health care utilization, and promptness for treatment in these two health insurance models in Nepal.

\section{Method}

This is an institution based concurrent mixed study consists of qualitative and quantitative variables from public and cooperative groups. We included all public HI operated by government hospitals and cooperatives groups those purchased hospital service in contract. Two separate study tools were applied to access the effectiveness of insurance models. The key questions were asked for the representatives of government and private health insurance. The numeric information consisted of in quantitative data and subjective response was included in qualitative approach. Descriptive statistics and Mean Whitney $\mathrm{U}$ test was applied in numeric data and qualitative information were analyzed by inductive approach

\section{Results}

The study revealed that new enrolment was not increased, health care utilization rate was increased and the benefit package was almost same in both groups. The overall inclusiveness was higher for the government HI, but enrolment from the religious minority, proportion of negotiated amount during treatment were significantly higher $(\mathrm{p}<0.05)$. During illness, the response time to reach hospital was significantly faster in cooperative health insurance than government health insurance. Qualitative findings showed that level of participation, accountability, transparency and recording system was better in cooperative health insurance than public. 


\section{Conclusion}

Cooperative HI could be more sustainable and accountable to the community for all; low, middle and high-income countries.

Key words: community-based health insurance; cooperative; benefit package; social inclusion; healthcare; Nepal

\section{Background}

In voluntary health insurance $(\mathrm{HI})$, community-based health insurance (CBHI) is attracting more and more attention in low- and middle-income countries as a means of improving health care utilization and to protect households against impoverishment caused by out-of-pocket medical expenditures. The World Health Organization and the World Bank have continuously suggested reducing out-ofpocket payments and promoting universal health coverage.[1, 2] Different health financing approaches have been developed to counter the detrimental effects of user fees introduced in the 1980s, but those efforts have not yet increased healthcare utilization, particularly among marginalised populations, and, moreover, sometimes lead to catastrophic health expenditures.[2-4] There are different models of health insurance; among them, CBHI is the most widely used among middleincome populations and in remote areas. CBHI has been implemented on a small scale in Nepal, but coverage remains relatively low.

As stated, there are different models of health insurance. Mandatory and single payer health insurance models are considered among the better approaches, but it is very difficult to collect premiums in low- and middle-income countries due to a lack of information technology.[5] Likewise, for people who are ultra-poor and live in rural areas, it is an additional challenge to enrol in health insurance. The only government approach is unable to provide universal healthcare because the primary responsibility for health falls upon each individual. The Obama administration purposed reducing healthcare costs and providing affordable health service using a cooperative concept in the US[6]; and, cooperative health insurance is replacing private health insurance in Canada.[7] Voluntary health insurances could be the step forward needed to lower risks associated with illness.

Two approaches to voluntary health insurance have been initiated both by the government and by local communities. Some studies have investigated the outcomes of CBHI in low-and middle-income countries, but their results have been inconsistent. Several previous reviews have evaluated the performance of CBHI in terms of enrolment, financial management, and sustainability.[8-10] One study of Laos indicated that government funded CBHI has low coverage, but the insured people typically have a significantly higher level of healthcare utilization, lower out-of-pocket payments (OPPs), lower incidence of catastrophic expenditures, and a lower propensity to employ coping mechanisms.[11] In a study in Ethiopia, out patients department (OPD) services increased, while inpatient department (IPD) services remained the same even after the implementation of CBHI.[12] Not only on low and middle countries, The Obama administration purposed reducing healthcare costs and providing affordable health service using a cooperative concept in the US[6]; and, cooperative health insurance is replacing private health insurance in Canada.[7]

There are some successful reports of voluntary health insurance by community initiatives, such as in Vietnam[13] and Japan,[14] and government initiatives in developing countries. In China, a New Cooperative Medical Scheme (NCMS) was piloted, and it had mixed results.[15] Similarly, the state 
government of Karnataka in India also made health insurance available to its people and tried to reduce OPPs and catastrophic health expenditure (CHE).[16] Previous studies have largely focused on the single model of CBHI, but a comparison of outcomes on government and co-operative $\mathrm{CBHI}$ models are rare globally, and none have focused on Nepal.

\section{Theoretical foundation}

International Cooperative Alliance (ICA) defined that a co-operative is an autonomous association of persons united voluntarily to meet their common economic, social, and cultural needs and aspirations through a jointly owned and democratically-controlled enterprise [17]. It further explored that cooperatives are based on the values of self-help, self-responsibility, democracy, equality, equity and solidarity. Similarly, cooperatives includes six basic principles; voluntary and open membership, democratic member control, member's economic participation, autonomy and independency, education training and information, cooperation among cooperatives and concern for the community. Previous experiences and after the assessment of Millinium Development Goal (MDG), there is a significant role of cooperative to reduce poverty and quality of health care. Cooperatives ensure healthy lives by creating the infrastructure for delivering healthcare services; financing healthcare and providing home-based healthcare services to people living with HIV/AIDS, among others [18]. There are three types of health cooperatives; consumer, service purchasing and worker cooperative [19] and due to small scale of economy of the cooperative groups, service purchasing cooperatives are popular in low and middle income countries. On the other side, government health insurance is a program that should implement through government health care system through their personnel. Centre government provide hospital management committee determine some budget (subsidy) and premium and benefit package. Enrolment is volunteer and some discount is given to the minority and ultra poor [20].

There are some successful reports of voluntary health insurance by community initiatives, such as in Vietnam[13] and Japan,[14] and government initiatives in developing countries. In China, a New Cooperative Medical Scheme (NCMS) was piloted, and it had mixed results.[15] Similarly, the state government of Karnataka in India also made health insurance available to its people and tried to reduce OPPs and catastrophic health expenditure (CHE).[16] Previous studies have largely focused on the single model of $\mathrm{CBHI}$, but a comparison of outcomes on government and co-operative $\mathrm{CBHI}$ models are rare globally, and none have focused on Nepal. In Nepal, there have been several experiments with CBHI reported since 2004 in both rural and urban settings.[21] Provider based health insurance was introduced in Nepal in 2003 through six pilot schemes offered by the government. At the same time, some community groups (coops) started CBHI by their own initiative supported by non-governmental organizations (NGOs).[22] CBHI schemes in Nepal complement a number of specialized programs for improving access to healthcare services.

The aim of the present study is to compare the outcomes of CBHI offered by government health facilities and those by community groups (co-ops) in terms of benefit packages, population coverage, inclusiveness, healthcare utilization, and promptness for treatment in Nepal. 


\section{Materials and methods}

\section{Study design}

The study is a descriptive cross-sectional of two CBHI models in 2014.

\section{Study approaches}

The researchers used a mix method approach both qualitative and quantitative data comparisons between two groups and synthesizing the results.[23] We used David Driscol et.al (2007) concurrent structure survey by applying open ended and closed questions with same respondents [24]. This method integrates research questions, employs rigorous quantitative research assessing magnitude, and explores the meaning and understanding of concepts; it utilizes multiple processes, and combines these to draw on their strengths; and, frames the investigation within philosophical and theoretical positions.[25] Recently, Creswell[26] emphasized that such an approach is better for philosophical, theoretical, and methodological perspectives. Qualitative research seeks to understand how individuals explore and perceive their experiences. Quantitative research is more powerful for the generalization of the findings; whereas, a combined approach is more valid, reliable, and replicable. Thus, the mixed impact of both designs is more powerful than a single approach. The use of "mixing" procedure in health services research involves the integration, connection, and embedding of these 2 data components [27].

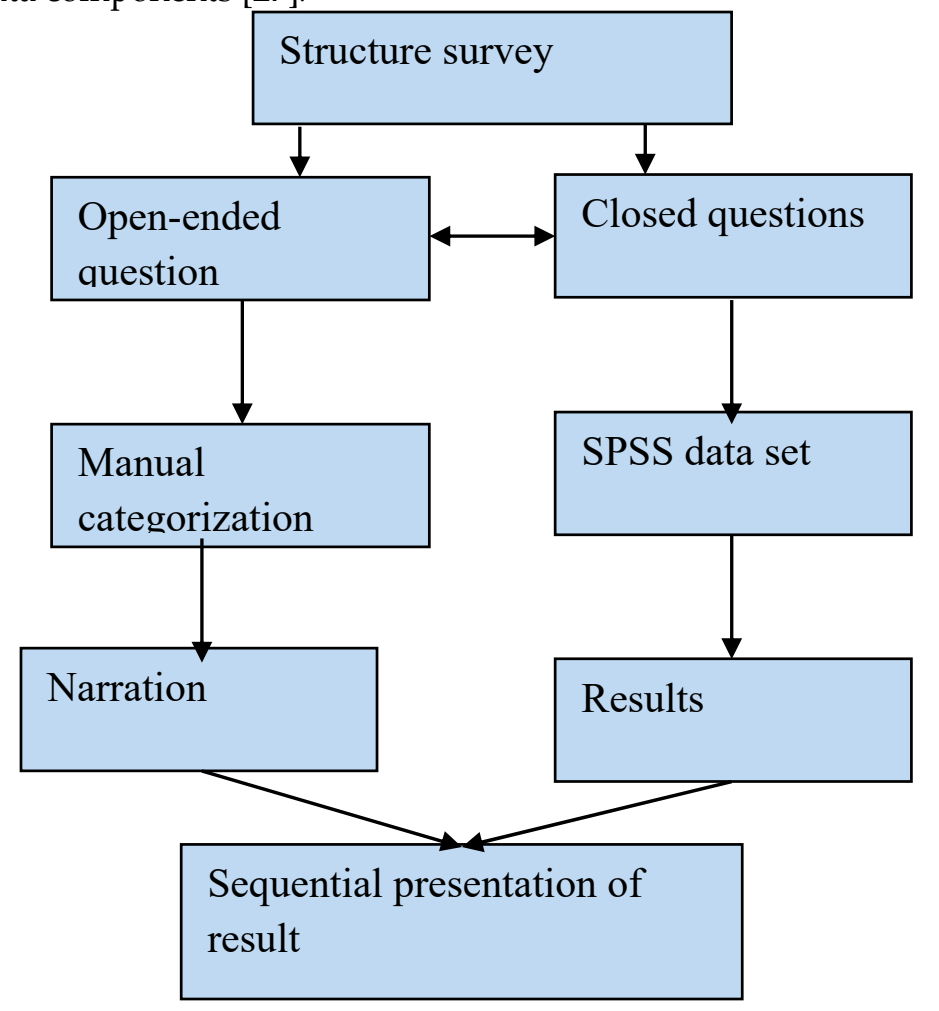

Concurrent mix study design: David 2007

\section{Study setting}

Being a concurrent mix study, we obtained the data from institution and opinion from key informants. The institutions were selected purposively and total 12 institutions were taken in which 6 were government health centres and 6 were coops conducted CBHI. The qualitative information was taken from responsible (focal person) of each government health centres and member secretary 
from coops. Their responses were categorised and presented in narrative form after the data results and summary statements were presented from each group.

\section{Study group and population}

We selected two models of community-based health insurance in Nepal.

Government-run, community-based health insurance (Group A): This group had six pilot areas, governed by the Ministry of Health and Population (MoHP) of Nepal, and based on a population surveyed more than five years prior. Primary health centres and district-level hospitals offered benefit packages of health insurance using their own management. They operated on government financing.

Co-operative prepayment health organization (Group B): This group had six community groups governed by these communities in collaboration with private and government hospitals. This model can be defined as a zero-cost financing model that empowers these community groups. There was some support from Non Government Organizations (NGOs), but this was in-kind support only. Funding came from their regular savings, subsidies, and donations from other organizations and some amount of benefits from group income generation activities.

\section{Study area}

The study area was selected from 12 pilot organizations that had managed government health facilities and co-operative organizations (Table 1).

Table 1: CBHI operated by Government of Community groups

\begin{tabular}{|lll|}
\hline $\begin{array}{l}\text { S.N. } \\
\text { CBHI conducted by government (established } \\
\text { year) }\end{array}$ & $\begin{array}{l}\text { Lamahi Primary Health Care Centre (2006) } \\
\text { (established year) }\end{array}$ & $\begin{array}{l}\text { Madhesa health post management } \\
\text { committee (2010) }\end{array}$ \\
\hline 2 & Tikapur Hospital (2006) & Syaphru (2009) \\
\hline 3 & $\begin{array}{l}\text { Mangalabare Primary Health Care Centre } \\
(2004)\end{array}$ & Rajmarga (2003) \\
\hline 4 & Dumkauli Primary Health Care Centre (2004) & Bikalpa (2001) \\
\hline 5 & $\begin{array}{l}\text { Chandranigahapur Primary Health Care } \\
\text { Centre (2006) }\end{array}$ & $\begin{array}{l}\text { Primary Health Care and Resource } \\
\text { Center(PHCRC), Chapagaun (1972) }\end{array}$ \\
\hline 6 & Katari Hospital (2006) & Saubhagya (2011) \\
\hline
\end{tabular}

\section{Study tools and technique}

Three sets of study tools were prepared for information collection.

Review of the records: Data were obtained from the logbooks, ledgers, enrolment registers, and meeting minutes of the health facilities and co-operative groups. From these, the characteristics and coverage levels of the enrolees were determined. The characteristics gathered included the enrolee age, gender, religion, and ethnicity. The following information was collected from each group's records: 
1. Did you have any targets for new enrolment in the last year?

1.1. If yes, did you have a special scheme for new enrolment?

2. What was the amount of the benefit packages you provided to the enrolee?

3. From your $\mathrm{CBHI}$, what is the covered population?

4. What is the composition of your enrolees (minorities, disadvantaged groups, poor, etc.) in relation to social inclusion?

5. What is the utilization rate of public health services among $\mathrm{CBHI}$ members?

6. Do you have any official contracts with health service providers (government and private hospitals)?

6.1. If yes, what kinds of agreements do you have (annually, bi-annually, etc.)?

7. Do you negotiate with health service providers within their standard price of treatment?

7.1. If yes, how much (Rupee or percentage)?

8. Do you have your own ambulance service to use during emergencies?

Key informant interview guidelines: The key informant interview guidelines were used to assess management's experience with CBHI. The informants were focal person of government health institution and member secretary of coops. In particular, the problems and challenges were obtained from the key informant interview process

1. When did you initiate the CBHI?

2. What are the problems with your $\mathrm{CBHI}$ ?

3. Who supports your group, and what kind of support do they provide?

4. What is your expectation from the government?

5. What suggestions do you have for the government and any supporting organizations?

6. How do you sustain the program in terms of governance and financial support?

Observation checklist: This checklist was prepared to identify the physical infrastructure, office setting, recording and reporting status, membership cards, registration, patient records, bank ledgers, and observation of income generation activities. Informal question-answer sessions, individual relationships, and breakfast and break time were utilized as techniques.

\section{Data management}

The data were divided into two parts. The numeric data were exported into Excel and analysed using the Statistical Package for the Social Sciences (SPSS) version 20. Likewise, the qualitative information was categorized into different groups. Common information was presented in a narrative form. 


\section{Data analysis}

In the first phase, the descriptive findings were plotted based on different categories related to enrolment, population coverage, and population composition. In the second phase, numeric data were analysed and tested statistically by applying the Mann-Whitney $U$ test as a two-group comparison. The qualitative information was analysed by inductive method and after analysed the results were integrated [28].

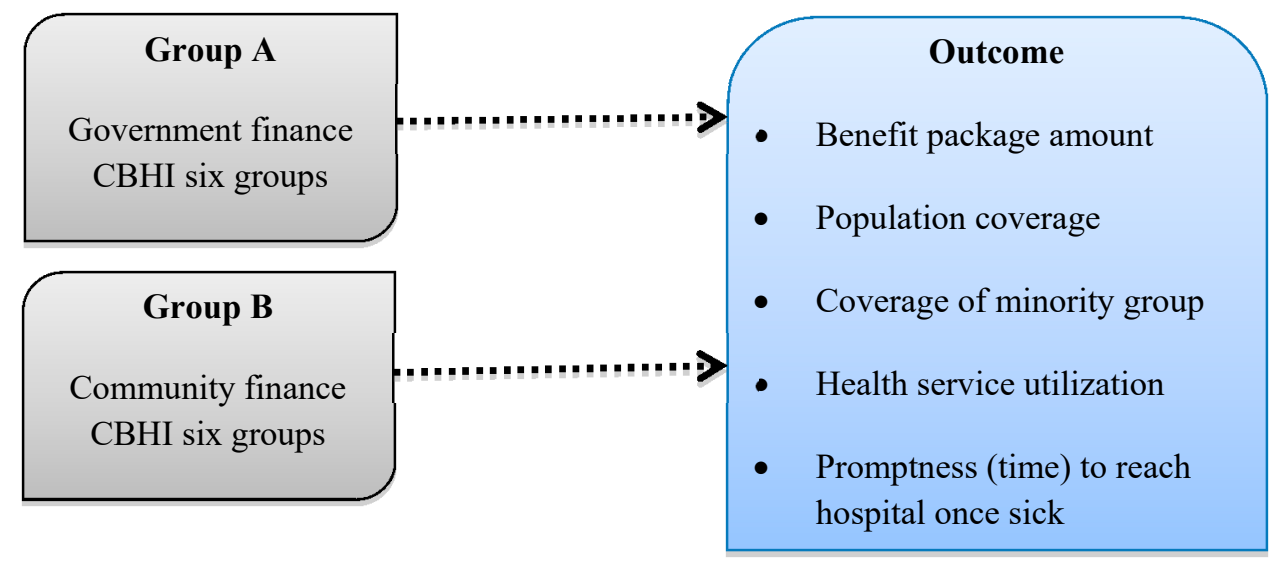

\section{Research outcome analysis}

This study was group-based, and the mean comparison of variables was included as like below research framework.

\section{Validity and reliability}

The results were synthesized carefully according to the data synthesis model of both qualitative and quantitative information. Numeric data were repeatedly checked by the appointed researcher and were cross-verified by other researchers. The tools were pre-tested in a similar community using video recordings. Necessary changes were made to the tools after the pilot study.

\section{Ethical consideration}

Study approval was granted by the Department of Health Service (DoHS) of Teku Kathmandu, Nepal and a formal letter was sent to the co-operatives and government health facilities. The research started after approval.

\section{Results}

Our study compared the outcomes of the government and the co-operative health insurance plans in Nepal. In the government CBHI, 1,422 households with 22,691 individuals were enrolled and 2,152 households with 10,106 individuals were enrolled in the co-ops. The composition of male and female was almost equal, domination of adult group, Hindu religion and mixed ethnicity were mostly involved in both CBHI models and enrolment was not satisfactory (low), and population coverage was minimal. The benefit package was slightly higher for the co-op group, while population coverage was better for the government group. Inclusiveness, overall management, and proxy activities were better in the co-op group (Table 2). 
Table 2: Descriptive comparison between government and community groups CBHI

\begin{tabular}{|c|c|c|c|}
\hline \multicolumn{2}{|l|}{ Indicators } & Government & Co-operative \\
\hline \multicolumn{4}{|c|}{ Enrolment and benefit package } \\
\hline \multicolumn{2}{|c|}{ Enrolment target } & Not achieved & Not fix target \\
\hline \multicolumn{2}{|l|}{ Scheme } & $\begin{array}{l}\text { No special subsidy beyond the } \\
\text { benefit package }\end{array}$ & $\begin{array}{l}\text { Some discounts for those who } \\
\text { want to enrol in groups and those } \\
\text { with a poor economic status }\end{array}$ \\
\hline \multicolumn{2}{|c|}{ Benefit package in Nepali rupees } & $\begin{array}{l}\text { Medicines, diagnostic } \\
\text { services, hospitalization, and } \\
\text { transportation (Rs 6000-20000) }\end{array}$ & $\begin{array}{l}\text { Medicines, diagnostic } \\
\text { services, hospitalization, and } \\
\text { transportation (Rs 6000-29000) }\end{array}$ \\
\hline \multirow{2}{*}{$\begin{array}{l}\text { Enrolment coverage } \\
(\%)\end{array}$} & New members & $3.4 \%$ & $2.4 \%$ \\
\hline & Renewal & Negative trend up to $47 \%$ & Constant \\
\hline \multicolumn{2}{|c|}{$\begin{array}{l}\text { Membership coverage in the catchment } \\
\text { area }(\%)\end{array}$} & 53 & 26 \\
\hline \multicolumn{4}{|c|}{ Enrolment composition } \\
\hline \multicolumn{2}{|c|}{ Religious minority (\%) } & 3 & 36 \\
\hline \multicolumn{2}{|c|}{ Disadvantaged Terai (\%) } & 2 & 3 \\
\hline \multicolumn{2}{|c|}{ Utilization of health services (\%) } & $134(42-162)$ & $212(6-320)$ \\
\hline \multicolumn{2}{|c|}{$\begin{array}{l}\text { Receiving a discount after negotiation } \\
(\%)\end{array}$} & 19 & 40 \\
\hline \multicolumn{2}{|c|}{ Scheme viability } & Less viable & Average \\
\hline \multicolumn{2}{|l|}{ Legal framework } & No legal framework in the MoHP & Legalized under co-operative law \\
\hline \multicolumn{4}{|l|}{ Management } \\
\hline \multicolumn{2}{|l|}{ Audit system } & Rarely audited & Regularly audited \\
\hline \multicolumn{2}{|l|}{ Software } & Not in practice & Computer recording \\
\hline \multicolumn{2}{|c|}{ Human resources for health insurance } & $\begin{array}{l}\text { Usual government personnel as } \\
\text { focal person }\end{array}$ & Secretary of coops \\
\hline \multicolumn{2}{|c|}{ Relationship with providers } & No contract with providers & $\begin{array}{l}\text { Two co-operatives have contracts } \\
\text { with providers at district and } \\
\text { regional hospitals }\end{array}$ \\
\hline \multicolumn{2}{|l|}{ Referral service } & $\begin{array}{l}\text { Referred by ambulance to their own } \\
\text { health centre or public vehicle }\end{array}$ & $\begin{array}{l}\text { All of them have their own } \\
\text { ambulance }\end{array}$ \\
\hline \multicolumn{2}{|l|}{ Subsidy } & From the government & None \\
\hline \multicolumn{2}{|l|}{ Sustainability } & Depends on government funding & $\begin{array}{l}\text { Have their own funds, but not } \\
\text { sufficient }\end{array}$ \\
\hline \multicolumn{4}{|l|}{ Proxy Indicators } \\
\hline \multicolumn{2}{|c|}{ Income generation activities } & No & $\begin{array}{l}\text { Yes } \\
\text { Cooperative vegetable farming } \\
\text { Poultry farming } \\
\text { Small livestock }\end{array}$ \\
\hline
\end{tabular}

Table 3 shows a comparison of the mean of each group variable examined in numeric data. The proportion of overall inclusiveness for the government group was significantly higher $(p<0.05)$ than that of the co-op group. However, the amount of negotiation and average response for treatment after 
illness/injury (initial and refer) to reach hospital was significantly better for the co-op group than the government health facilities.

Table 3: Comparison of health indicators between the two CBHI models

\begin{tabular}{|c|c|c|c|}
\hline Variables & $\begin{array}{l}\text { Type of } \\
\text { organization }\end{array}$ & Mean \pm SD & $p$-value \\
\hline \multirow[t]{2}{*}{ Amount of benefit package in Rupees } & Government & $14,333 \pm 6,274$ & 0.108 \\
\hline & Co-operative & $45,775 \pm 43,184$ & \\
\hline \multirow{2}{*}{$\begin{array}{l}\text { Coverage population per group or } \\
\text { health centre }\end{array}$} & Government & $3,781 \pm 1,945$ & 0.057 \\
\hline & Co-operative & $1,684 \pm 1,390$ & \\
\hline \multirow{2}{*}{$\begin{array}{l}\text { Coverage of overall inclusiveness in } \\
\text { numbers per group or health centre }\end{array}$} & Government & $1,930 \pm 1,120$ & 0.010 \\
\hline & Co-operative & $417 \pm 362$ & \\
\hline \multirow{2}{*}{$\begin{array}{l}\text { Inclusiveness of religious minorities in } \\
\text { numbers }\end{array}$} & Government & $78 \pm 56$ & 0.048 \\
\hline & Co-operative & $547 \pm 523$ & \\
\hline \multirow{2}{*}{$\begin{array}{l}\text { Inclusiveness of disadvantaged Terai } \\
\text { in } \%\end{array}$} & Government & $64 \pm 100$ & 0.940 \\
\hline & Co-operative & $70 \pm 168$ & \\
\hline \multirow[t]{2}{*}{ Health service utilization rate in $\%$} & Government & $107 \pm 43$ & 0.524 \\
\hline & Co-operative & $137 \pm 102$ & \\
\hline \multirow{2}{*}{$\begin{array}{l}\text { Proportion of discounts after } \\
\text { negotiation in } \%\end{array}$} & Government & $18 \pm 10$ & 0.003 \\
\hline & Co-operative & $40 \pm 7$ & \\
\hline \multirow{2}{*}{$\begin{array}{l}\text { Average response for treatment after } \\
\text { illness/injury (initial and refer) to } \\
\text { reach hospital in minutes }\end{array}$} & Government & $118 \pm 38$ & 0.008 \\
\hline & Co-operative & $38 \pm 45$ & \\
\hline
\end{tabular}

\section{Results from the key informant interviews}

A similar result was found during the key informant interviews. Both representatives expressed that there was less interest among people in new enrolment. During the observations and conversations with key informants, the following results were found.

Although many people receive services from the government health facilities, the services offered were not promoted to insured patients to promote health insurance. Health workers and other personnel lacked experience in health insurance management and realized that they could not provide priority to insured patients or encourage new enrolment because the staff already had high 
workloads. The allocated budget was not recorded properly and used for administrative purposes (travelling and daily allowance). The experience from the representative focal person at the government health facilities was captured as follows:

There are no extra human resources for health insurance, and we have to perform duties related to public health and curative services at this health facility. We have no time to go out in the community to convince people to obtain health insurance or other special benefit for insured people. The enrolment of individuals in the higher social classes is rare, but the levels of participation from other groups are acceptable. We are taking extra responsibility work regarding health insurance but receive no additional incentives. There is a very limited budget from the government; and, they do not release it time. We are also not trained in health insurance and have no previous experience with it, so we have difficulty recording and reporting as required. However, if the government mandates health insurance for all health facilities, the program will become consistent, and trained human resources will be appointed.

Community groups had different experiences. Some NGOs supported the building of capabilities, such as training, workshops, and materials (whereas, the government did not provide such support to its group). These co-op groups maintained records properly in comparison with the government health facilities, but the recording systems were not consistent. At the time of this study, they were just starting to use computer-based records for each patient, expenditures, and other important decisions. They had collected more funds from their members and minimized administrative costs. Due to their strong negotiating skills, they had saved some money during service contracts with hospitals and invested this into other income generation activities. There was quite a different conversation with the representative member from the co-ops:

The government does not provide us with any subsidy. The NGOs provide some occasional support, and they rely on us to train our staff and provide some materials for the office. We have managed all activities related to health insurance by ourselves. We have started some income generation activities in our group such as vegetable farming, poultry farming, and live stock management, and we have our own ambulance to carry people who need transport to the hospital. We manage all efforts for our group members; volunteers do almost all the work and therefore there is minimum cost in administration. Up to now, nobody in our group has been deprived of treatment during an illness or faced catastrophic health expenditures. If the government provided some subsidy, we could also enrol ultra-poor groups. With our limited resources, we are doing our best.

The study revealed that new enrolment was not increased, health care utilization rate was increased and the benefit package was almost same in both groups. The overall inclusiveness was higher for the government HI, but enrolment from the religious minority, proportion of negotiated amount during treatment were significantly higher $(\mathrm{p}<0.05)$. During illness, the response time to reach hospital was significantly faster in cooperative health insurance than government health insurance. Qualitative findings showed that level of participation, accountability, transparency and recording system was better in cooperative health insurance than public.

\section{Discussion}

This study clearly shows the characteristics of the two models of CBHI in Nepal. The population coverage was significantly higher in the government conducted CBHI, but inclusiveness and institutional capacity were stronger in the co-ops. Health insurance has been in operation in Nepal 
for a long time on a small scale, but the Ministry of Health and Population (MoHP) has been unable to establish milestone target for universal health care (UHC). This is because achieving UHC is still challenging. The whole labour market has not been defined and is not linked through a banking system. As a result, it is difficult to collect health insurance premiums and about one quarter of the population is still using traditional and complementary medicine in Nepal.[29] Likewise, there is a lack of a legal framework as well as operating guidelines for health insurance in Nepal. Thus, the CBHI approach could be an effective approach to achieve curative health service. The current enrolment status indicates that the government was unable to convince people to share the costs during illness. Existing government $\mathrm{CBHI}$ programs are not attractive to people and the co-op CBHI had poor coverage as well but with a positive direction. User fees, community drug programs, and free health service policies in past have created confusion among individuals looking to enrol in CBHI.[30]

There are some pros and cons concerning the community health-financing scheme. We found comparatively large coverage and relatively flexible premiums (in terms of payment schedules) and subsidies for the ultra-poor in the government run CBHI. However, in this model, the local communities were unable to take ownership and there was very low utilization of the resources. In contrast, in the co-ops pre-payment $\mathrm{CBHI}$, this approach engendered trust and a feeling of ownership. A similar conclusion was drawn by Mebratie[31] in a systematic review published in 2013.

In looking at our results and comparing these to other studies, we found similar trends. Enrolment is the first step in any CBHI model. Based on the large number of enrolees, the average enrolment was significantly higher in the government CBHI model, but the number of disadvantaged minorities was significantly higher in the co-op group. This finding is similar to results in a study in India that women in self-help groups found more inclusiveness among minority populations.[32] In both groups, health care utilization increased significantly (up to two times), and this condition was also observed in the Sky community group in Cambodia[33], the Grameen Bank group in Bangladesh[34], the government Amhims group in Ghana[35], Jaminan Kesehatan Aceh (JKA) scheme in Indonesia[36] the Mutelleus Government Center in Rwanda[37], Kerala India[38] and Vietnam.[39] At the same time, coverage of the population in the catchment area was low in both groups. The same trend was observed in the People's Democratic Republic of Laos.[11] New enrolment and retention of current enrolees was low in both models due to uncertain financial viability, quality of care, long waiting time for treatment, and proper management of health care providers, similarly to conditions in Ghana.[40]

Yeshavani is co-operative CBHI provider in India,[41] and Urban Resident Basic Medical Insurance (URBMI) has the same function in China[42] as like government CBHI model in Nepal. In both cases, people from remote areas and those in a higher education class were not interested in enrolment, similarly to a trend in Mali[43] and findings are similar trend with our results. The number of new enrolees has been decreasing in the Hanang district of Tanzania,[44] as in the government CBHI in our study. Enrolment of members of the Terai disadvantaged group was significantly higher in the co-op insured group; this finding is similar to the results from the SEWA group in India,[45] but the Nouna community health organization in Burkina Faso[46] and the Les mutealle de santé in Senegal[47] have not been able to cover disadvantaged groups.

The discounts provided during service contracting with hospitals were significantly larger $(p<0.05)$ for the co-op group (by effective negotiation skills) versus the government public health centres. This 
is not only beneficial for the sustainability of the health insurance industry but also empowers individual and institutional capabilities.

In India, it was concluded that people's negotiating power reduced the costs and improved the quality of service.[48] In Canada, per patient cost was 17\% lower than the average price; hospitalization rates were up to $30 \%$ lower, and $21 \%$ less money was spent on prescription drugs[49] in co-operative health insurance versus private health insurance. In China, the operating capacity of a CBHI is significantly higher in a new co-operative medical scheme (NCMS) than it is in a government health insurance scheme.[50] In addition, health service quality and co-operative health insurance in Canada are equally concerned with profit generating activities.[51] The results from Canada and China were similar to our findings.

The health insurance industry in Nepal has been in existence for a long time, but coverage is still low and there are only a few successful CBHI models. The health insurance plans offered by co-operative groups are a newly growing strategic movement in health service in the country. With proper subsidies from the government and long-term contracts with advanced hospitals, health insurance offered by community groups could be more effective as an almost zero cost financing model and health equity and quality of service in Nepal could be more accessible to people. Nevertheless, there are some limitations in our study. There was not sufficient variables to compare co-operative and government health insurance. However, as a whole, CBHI has achieved limited success in terms of community participation, self-health care, and social unity. Thus, significant support is still necessary for both CBHI models as shown in the case of East Africa.[52] There are different minority groups in Nepal and inconsistence region by region. So, overall inclusiveness, religious minority and disadvantage Terai group are not equal proportion in both groups. The results of this study are from the supply side (government health facilities and community groups) and conclusions may differ when the demand side (consumers) is examined. Additionally, some information from the key people interviewed may be more subjective and thereby there is a risk in generalization.

\section{Conclusion}

Community health insurance programs have multiple and long-term impacts because they can reduce the financial pressure on the government and be responsible for maintaining health and empowering people. More importantly, it is applicable to reduce the out of pocket expenditure and reduce catastrophic health expenditures[53] for newly designated community groups in developing countries, especially those in remote areas and for people in urban areas who cannot afford private health care. Ultimately, successful CBHI models could be milestone to achieve Universal Health Care (UHC).

\section{Competing of interest}

The authors declare that they have no competing interests

\section{Funding}

GIZ, the Ministry of Health and Population in Nepal, the Korean Medical Association (RIHP-201502), and the National Research Foundation (NRF-2013S1A5B8A01055336), Korea, supported this study 


\section{References}

1. Organization WH: Health systems financing: The path to universal coverage. Geneva: WHO. In.; 2010.

2. Hsiao W, Shaw R, Fraker A, Hanvoravongchai P, Jowett M, Pinto D, Ramachandra S: Social health insurance for developing nations. Washington DC: WBI Development Studies, World Bank; 2006.

3. Devadasan N, Criel B, Van Damme W, Ranson K, Van der Stuyft P: Indian community health insurance schemes provide partial protection against catastrophic health expenditure. BMC Health Services Research 2007, 7:43.

4. McIntyre D, Thiede M, Dahlgren G, Whitehead M: What are the economic consequences for households of illness and of paying for health care in low-and middle-income country contexts? Social Science $\mathcal{E}$ Medicine 2006, 62:858-865.

5. Savedoff WD, Gottret PE: Governing mandatory health insurance: learning from experience: World Bank Publications; 2008.

6. Marmor T, Oberlander J, White J: The Obama administration's options for health care cost control: Hope versus reality. Annals of Internal Medicine 2009, 150:485-489.

7. Law MR, Kratzer J, Dhalla IA: The increasing inefficiency of private health insurance in Canada. Canadian Medical Association Journal 2014:cmaj. 130913.

8. Carrin G, Waelkens MP, Criel B: Community-based health insurance in developing countries: A study of its contribution to the performance of health financing systems. Tropical Medicine E International Health 2005, 10:799-811.

9. Ekman B: Community-based health insurance in low-income countries: A systematic review of the evidence. Health Policy and Planning 2004, 19:249-270.

10. Baeza C, Montenegro F, Núñez M: Extending social protection in health through community based health organizations: Evidence and challenges. In: Universitas Programme, International Labour Organisation/Strategies and Tools against Social Exclusion and Poverty, Geneva. Geneva International Labor Organization; 2002.

11. Alkenbrack S, Lindelow M: The impact of community-based health insurance on utilization and out-of-pocket expenditures in lao people's democratic republic. Health Economics 2013, 14:379-399.

12. Mebratie AD, Sparrow R, Yilma Z, Abebaw D, Alemu G, Bedi A: Impact of Ethiopian pilot community-based health insurance scheme on health-care utilisation: A household panel data analysis. The Lancet 2013, 381:92.

13. Jowett $M$, Contoyannis $P$, Vinh ND: The impact of public voluntary health insurance on private health expenditures in Vietnam. Social Science \& Medicine 2003, 56:333-342.

14. Ogawa S, Hasegawa T, Carrin G, Kawabata K: Scaling up community health insurance: Japan's experience with the 19th century Jyorei scheme. Health Policy and Planning 2003, 18:270-278.

15. Wagstaff A, Lindelow M, Jun G, Ling X, Juncheng Q: Extending health insurance to the rural population: An impact evaluation of China's new cooperative medical scheme. Journal of Health Economics 2009, 28:1-19.

16. Sood N, Bendavid E, Mukherji A, Wagner Z, Nagpal S, Mullen P: Government health insurance for people below poverty line in India: Quasi-experimental evaluation of insurance and health outcomes. BMJ 2014, 349:g5114.

17. Cooperative enterprises builds a better world [http://ica.coop/en/what-co-operative]

18. Wanyama FO: Cooperatives and the Sustainable Development Goals: A contribution to the post-2015 development debate: ILO; 2014.

19. Health Care Cooperatives: Definitions and State Examples [http://www.aafp.org/dam/AAFP/documents/advocacy/coverage/insurance/ESHealthCareCooperativesDefinitionsandStateExamples-032311.pdf] 
20. Acharya A, Vellakkal S, Kalita S, Taylor F, Satija A, Burke M, Masset E, Tharyan P, Ebrahim $S$ : Do social health insurance schemes in developing country settings improve health outcomes and reduce the impoverishing effect of healthcare payments for the poorest people. In: 2011; 2011.

21. Stoermer M, Fuerst F, Rijal K, Bhandari R, Nogier C, Gautam GS, Hennig J, Hada J, Sharma S: Review of community-based health insurance initiatives in Nepal. In.: Deutsche Gesellschaft fur internationale Zusammenarbeit (GIZ) Gmbh; 2012.

22. Magar A: Envisaging beyond community-based health insurance in Nepal. Journal of Nepal Health Research Council 2014, 11:1-3.

23. Greene JC: Mixed methods in social inquiry, vol. 9. USA John Wiley \& Sons; 2007.

24. Driscoll DL, Appiah-Yeboah A, Salib P, Rupert DJ: Merging qualitative and quantitative data in mixed methods research: How to and why not. Ecological and Environmental Anthropology 2007, 3:18.

25. Johnson RB, Onwuegbuzie AJ, Turner LA: Toward a definition of mixed methods research. Journal of Mixed Methods Research 2007, 1:112-133.

26. Creswell JW: Research design: Qualitative, quantitative, and mixed methods approaches. United Kingdom: Sage Publications; 2013.

27. Zhang W, Creswell J: The use of "mixing" procedure of mixed methods in health services research. Medical Care 2013, 51(8):e51-e57.

28. Spencer L, Ritchie J, O'Connor W: Qualitative research practice London: SAGE Publication; 2003.

29. Chhabi R, Do Y, Ahn D, Lee K, Kim C: Changing Pattern of Complementary and Alternative Medicine in Tikapur Nepal: A Hope for Future Health. Alternative $\mathcal{E}$ Integrative Medicine 2014, 2014.

30. Sato M, Gilson L: Exploring health facilities' experiences in implementing the free healthcare policy (FHCP) in Nepal: How did organizational factors influence the implementation of the user-fee abolition policy? Health Policy and Planning 2015, 2015:17.

31. Mebratie A, Sparrow R, Alemu G, Bedi AS: Community-Based Health Insurance Schemes. In: ISS Working Paper Series/General Series. vol. 568; 2013: 1-47.

32. Panda P, Chakraborty A, Dror DM, Bedi AS: Enrolment in community-based health insurance schemes in rural Bihar and Uttar Pradesh, India. Health Policy and Planning 2013, 29:960 -974.

33. Levine D, Polimeni R, Ramage I: Insuring health or insuring wealth: Report. In: $A n$ experimental evaluation of health insurance in rural Cambodia. 2012.

34. Hamid SA, Roberts J, Mosley P: Can micro health insurance reduce poverty? Evidence from Bangladesh. Journal of Risk and Insurance 2011, 78:57-82.

35. Gobah FK, Zhang L: The national health insurance scheme in ghana: Prospects and challenges: A cross-sectional evidence. Global Journal of Health Science 2011, 3:90.

36. Kesuma ZM, Chongsuvivatwong V: Utilization of the Local Government Health Insurance Scheme (JKA) for maternal health services among women living in underdeveloped areas of Aceh Province, Indonesia. Asia-Pacific Journal of Public Health 2014, 27(3):348-359.

37. Shimeles A: Community based health insurance schemes in Africa: The case of Rwanda. In: Working Papers in Economics. vol. 463; 2010.

38. Philip NE, Kannan S, Sarma SP: Utilization of Comprehensive Health Insurance Scheme, Kerala A Comparative Study of Insured and Uninsured Below-Poverty-Line Households. Asia-Pacific Journal of Public Health 2016, 28(1 suppl):77S-85S.

39. Wagstaff A: Health insurance for the poor: Initial impacts of Vietnam's health care fund for the poor. World Bank Policy Research Working Paper 2007(4134).

40. Dixon J, Tenkorang EY, Luginaah I: Ghana's National Health Insurance Scheme: a national level investigation of members' perceptions of service provision. $B M C$ International Health and Human Rights 2013, 13:1. 
41. Aggarwal A: Impact evaluation of India's 'Yeshasvini'community-based health insurance programme. Health Economics 2010, 19:5-35.

42. Chen G, Yan X: Demand for voluntary basic medical insurance in urban China: Panel evidence from the Urban Resident Basic Medical Insurance scheme. Health Policy and Planning 2012, 27:658-668.

43. Franco LM, Diop FP, Burgert CR, Kelley AG, Makinen M, Simpara CHT: Effects of mutual health organizations on use of priority health-care services in urban and rural Mali: $A$ case-control study. Bulletin of the World Health Organization 2008, 86:830-838.

44. Musau S: The Community Health Fund: Assessing implementation of new management procedures in Hanang district Tanzania. In.; 2004.

45. Gumber A: Hedging the health of the poor: The case for community financing in India. In.; 2001: 32.

46. Gnawali DP, Pokhrel S, Sié A, Sanon M, De Allegri M, Souares A, Dong H, Sauerborn R: The effect of community-based health insurance on the utilization of modern health care services: Evidence from Burkina Faso. Health Policy 2009, 90:214-222.

47. Jütting JP: Do community-based health insurance schemes improve poor people's access to health care? Evidence from rural Senegal. World Development 2004, 32:273-288.

48. Michielsen J, Criel B, Devadasan N, Soors W, Wouters E, Meulemans H: Can health insurance improve access to quality care for the Indian poor? International Journal for Quality in Health Care 2011, 23:471-486.

49. Angus DE, Manga P, Association CC: Coop-consumer Sponsored Health Care Delivery Effectiveness: Canadian Cooperative Association; 1990.

50. Yan F, Raven J, Wang W, Tolhurst R, Zhu K, Yu B, Collins C: Management capacity and health insurance: The case of the New Cooperative Medical Scheme in six counties in rural China. The International Journal of Health Planning and Management 2011, 26:357-378.

51. MacKay L: Health cooperatives in British Columbia: The unmet potential. British Columbia Medical Journal 2007, 49:139.

52. Musau SN: Community-based health insurance: Experiences and lessons learned from East Africa. In.; 1999.

53. Lee W-Y, Shaw I: The impact of out-of-pocket payments on health care inequity: The case of national health insurance in South Korea. International Journal of Environmental Research and Public Health 2014, 11:7304-7318.

(C) 2016 by the authors; licensee Preprints, Basel, Switzerland. This article is an open access article distributed under the terms and conditions of the Creative Commons by Attribution (CC-BY) license (http://creativecommons.org/licenses/by/4.0/). 